\title{
APLIKASI JAIM (JIWASRAYA AGENCY INFORMATIONS MANAGEMENT) SEBAGAI MEDIA INFORMASI AGEN DI PT. ASURANSI JIWASRAYA (persero) PEKANBARU
}

\author{
Rosmala \\ Ilmu Komunikasi STISIP Persada Bunda \\ rosmala.lbs@gmail.com
}

\begin{abstract}
Abstrak
Penelitian ini bertujuan untuk mengetahui efektivitas komunikasi aplikasi JAIM( Jiwasraya Agency Information Management) sebagai media informasi untuk kegiatan sehari harinya.dan dapat dalam rangka merealisasikan potensial aplikasi JAIM sesui kebutuhan Efektivitas komunikasi aplikasi JAIM membawa perubahan terhadap agen. Metodologi penelitian ini menggunakan deskriftif kualitatif.teknik pengumpulan data wawancara,observasi dan dokumentasi,internet searching. informan adalah senior agency manager, agen, nasabah. Hasil penelitian aplikasi sebagai efektivitas komunikasi aplikasi JAIM sebagai media informasi agen belum efektif karena berdasarkan tiga efek yaitu : 1) efek kognitif : Aplikasi JAIM yang digunakan masih kurang efektif karena masih ada sebagian agen yang kurang memahami aplikasi JAIM. 2) efek afektif : aplikasi JAIM membawa efek perubahan pada agen di era digital,media online untuk bisa mengaplikasikan JAIM. 3) efek behavioral : memberikan efektivitas komunikasi agen terhadap Keterampilan yang tercipta dan proses pembelajaran aplikasi JAIM. Aplikasi JAIM yang diperuntukkan mitra kerja agen jiwasraya masih error system. Aplikasi JAIM yang merupakan Media infomasi terdapat beberapa menu seperti beranda,pencapaian,prestasikontes, workbook,buat proposal,learning,espaj,ekpaj,my Pro sales.Diharapkan aplikasi JAIM ini membawa peruhaan sehingga efektivitas komunikasi agen menggunakan aplikasi JAIM memberikan efek yang laur biasa serta aplikasi JAIM yang sudah disediakan oleh PT. Asuransi jiwasraya (persero) pekanbaru diharapkan dapat membantu agen mampu mengaplikasikan JAIM secara efektif.
\end{abstract}

\section{Kata Kunci : Efektivitas Komunikasi, Media Informasi, JAIM}

\begin{abstract}
This study aims to determine the effectiveness of JAIM application communication (Jiwasraya Agency Information Management) as a medium of information for daily activities. And can be in order to realize the potential of JAIM applications according to the needs The effectiveness of JAIM application communication brings changes to agents. This research methodology uses qualitative descriptive. Interview data collection techniques, observation and documentation, internet searching. informants are senior agency managers, agents, customers. The results of application research as the effectiveness of JAIM application communication as a media information agent have not been effective because based on three effects, namely: 1) cognitive effects: JAIM application used is still less effective because there are still some agents who do not understand the JAIM application. 2) affective effect: JAIM application brings the effect of change on agents in the digital age, online media to be able to apply JAIM. 3) behavioral effect: provides the effectiveness of agent communication on the skills created and the learning process of the JAIM application. The JAIM application that is intended for partners of psychiatric agents is still an error system. JAIM application,
\end{abstract}


which is an information media, has several menus such as the homepage, achievements, contest achievements, workbooks, making proposals, learning, espaj, exp. JAIM application that has been provided by PT. Jiwasraya (Persero) insurance is expected to help agents be able to apply JAIM effectively

\section{Keywords: Communication Effectiveness, Information Media, JAIM}

\section{A. PENDAhULUAN}

Saat ini perkembangan teknologi Internet sudah mencapai perkembangan yang sangat pesat.Aplikasi Internet sudah digunakan untuk e-commerce dan berkembang kepada pemakaian aplikasi Internet pada lingkungan masyarakat luas. yang dikenal dengan egovernment dan media online. Efektivitas merupakan wujud dari kemampuan untuk mendayagunakan sesuatu secara tepat sesuai dengan standar yang jelas dan dapat diterima secara universal.Dalam konteks ini efektivitas menunjukkan taraf mencapai tujuannya secara ideal, taraf efektivitasnya dapat dinyatakan dengan ukuran-ukuran yang pasti.Efektivitas adalah kemampuan untuk mencapai suatu tujuan dengan ukuran yang pasti. Efektivitas adalah suatu keadaan yang menunjukkan tingkat keberhasilan atau pencapaian suatu tujuan yang diukur dengan kualitas, kuantitas, dan waktu, sesuai dengan yang telah direncanakan sebelumnya.

Efektivitas sangat berhubungan dengan terlaksananya semua tugas pokok, tercapainya tujuan, ketepatan waktu, serta adanya usaha atau partisipasi aktif dari pelaksana tugas tersebut.brdasarkan feneomena dilapangan untuk memeprmudah sistem kerja diera digital dan media online PT.Asuransi Jiwasraya (persero) pekanbaru harus update dan mengikuti perubahan ERA 4.0 melalaui Aplikasi JAIM.industry Jasa Keuangan harus mengikuti teknologi yang semakin berkembang. Khususnya PT. Asuransi Jiwasraya (persero) Pekanbaru selalu ingin terus menggali lebih dalam lagi inovasi-inovasi baru dalam rangka mempermudah kinerja agen sebagai Mitra di Jiwasraya. ada saat ini, semuanya sedang berfokus kepada revolusi industri 4.0.semua beralih ke arah modern dan sangat teknologi. Semua berharap dari teknologi dan bergantung dari teknologi juga.Era Industri 4.0 akan terus menghadirkan banyak perubahan yang tak bisa dibendung. Agen di PT Asuransi Jiwasraya (persero) Pekanbaru seperti, Area Manager, Unit Manager, Finacial Advisor, memang sudah menjalani beberapa perubahan itu, tetapi kepedulian pada tantangan di era digitalisasi dan optimalisasi sekarang ini pun terbilang minim atau belum efektif.perkembangan industri 4.0 yang modern ini munculah yang namanya aplikasi-aplikasi terbaru di media online, seperti aplikasi JAIM (Jiwasraya Agency Information Management)aplikasi JAIM disini adalah salah satu aplikasi yang membuat berbagai informasi-informasi penting terkait dengan kegiatan-kegiatan yang dilakukan oleh Jiwasraya, memberikan informasi kepada agency dan mempermudah bagi pengelola maupun Agen Jiwasraya Pekanbaru.

\section{B.TINJAUAN PUSTAKA}

\section{Efektivitas Komunikasi}

Efektivitas secara umum menunjukan sampai seberapa jauh tercapainya suatu tujuan yang terlebih dahulu ditentukan.Hal tersebut sesuai dengan pengertian efetivitas menurut Moore D.Kenneth Dalam Moh Syarif (2015:1).Efektivitas suatu ukuran yang menyatakan seberapa jauh target (kuantitas, kualitas dan waktu) telah tercapai, atau makin besar presentase target yang dicapai, makin tinggi efektivitasnya. Efektivitas Menurut Ravianto "2014:11". Efektivitas Ialah Seberapa baik pekerjaan yang dilakukan, sejauh mana orang menghasilkan keluaran sesuai dengan yang iharapkan. Artinya apabila suatu pekerjaan dapat diselesaikan sesuai dengan perencanaan, baik dalam waktu, biaya, maupun mutunya maka dapat dikatakan 
Efektif. Efektivitas komunikasi merupakan suatu proses penyampaian pesan yang mampu mencapai tujuan dari isi pesan tersebut dan memberikan umpan balik (feed Back) atau reaksisehingga pesan pun berhasil tersampaikan dan menimbulkan sebuah komunikasi yang efektif.Menurut jalaluddin Rahmat RakhmaT(2013) efektivitas komunikasi akan membawa efek pada tataran yaitu;

a. Efek kognitif, yaitu terjadi jika ada perubahan pada apa yang dikethui, dipahami dan dipersepsi oleh khalayak

b. Efek Afektif, yaitu timbul jika ada perubahan pada apa yang dirasakan, disenangi atau dibenci khalayak

c. Efek Behavioral, yaitu merujuk pada perilaku nyata yang dapt diamati, yang meliputi pola-pola tindakan, kegiatan atau kebiasaan perilaku

\section{Media Informasi}

Media dikatakan pula sebagai segala bentuk dan saluran yang digunakan orang untuk menyalurkan pesan/informasi. Makna bahwa media tidak terbatas pada jenis media yang dirancang secara khusus untuk mencapai tujuan tertentu tetapi keberadaannya dapat mempermudah atau memperjelas pemahaman siswa terhadap materi atau pesan tertentu, jadi dalam bentuk apapun apabila dapat menyalurkan pesan dapat disebut sebagai media. (Prasetya,2015).media informasi adalah "alat-alat grafis, fotografis atau elektronis untuk menangkap, memproses, dan menyusun kembali informasi visual sobur (2006).

\section{Agen}

Agen asuransi adalah tenaga profesional yang memasarkan dan mendistribusikan produk asuransi. Dalam bahasan ini produknya adalah asuransi jiwa. Semua pelaku profesi agen asuransi harus memiliki lisensi. Untuk mendapatkan lisensi, seorang agen perlu mengambil kursus terakreditasi dan lulus ujian. Di Indonesia, lisensi ini dikeluarkan oleh Asosiasi Asuransi Jiwa Indonesia (AAJI). Menurut J.T. Sianipar, sebagaimana dikutip oleh Abdul Muis, agen asuransi merupakan perantara dari perusahaan asuransi dengan pihak tertanggung baik dalam penutupan pertanggungan maupun dalam penyelesaian klaim.Menurut Pasal 1 Ayat 10 Undang Undang Nomor 2 Tahun 1992, agen asuransi adalah seseorang atau Badan Hukum yang kegiatannya memberikan jasa dalam memasarkan jasa asuransi untuk dan atas nama Penanggung.

\section{JAIM}

Aplikasi JAIM adalah (Jiwasraya Agency Information Management) khusus untuk agen pemasar jiwasraya guna membantu proses penjualan produk asuransi di lapangan.dengan JAIM,agen pemasar tidak perlu lagi membuat proposal dikantor jiwasraya,melainkan dapat langsung mengakses JAIM dimanapun dan kapanpun agar menghemat waku

\section{Metodologi Penelitian}

Jenis penelitian ini adalah deskriptif kualitatif, yaitu menyajikan atau secara deskriftif berupa kata kata tertulis secara mendalam.pendekatan ini mementingkan pada makna dan bukan kuantitas.desain penelitian ini bersifat sementara dan fleksibel,yakni desain dapat disesuiakan karena terus menerus sesuai kenyataan dilapangan.hal ini dikarenakan tidak dapat dibayangkan kenyataan -kenyataan yang ada dilapangan kemudian tidak dapat diprediksi perubahan perubahan yang terjadi,bermacam sistem nilai terkait berhubugan dengan cara yang tidak dapat diramalkan (Prastowo,2016,p.44).tekhnik pengumpulan data observasi, wawancara,dokumentasi. 


\section{HASIL DAN PEMBAHASAN}

\section{Efektivatas komunikasi Aplikasi JAIM}

Efektivitas komunikasi merupakan suatu proses penyampaian pesan yang mampu mencapai tujuan dari isi pesan tersebut dan memberikan umpan balik (feed Back) atau reaksi sehingga pesan pun berhasil tersampaikan dan menimbulkan sebuah komunikasi yang efektif. efektivitas dapat diartikan suatu keadaan yang menunjukkan tingkat keberhasilan atau pencapaian suatu tujuan yang diukur dengan kualitas, kuantitas, dan waktu, sesuai dengan yang telah direncanakan sebelumnya. Sehingga dalam penelitian ini peneliti telah mendapatkan hasil yang diukur dengan deskriftif kualitatif aplikasi JAIM yang tersedia sebagi media informasi untuk agen masih menunjukkan hasil yang kurang efektif. tingkat keberhasilan agen di PT. Asuransi Jiwasraya (persero) menggunakan aplikasi JAIM sebagai media informasi dihasilkan oleh age atau unit kerja dengan cara tertentu sesuai dengan tujuan yang hendak dicapai. Dengan kata lain, semakin banyak rencana yang berhasil dicapai maka suatu kegiatan dianggap semakin efektif. Berdasarkan hal tersebut dapat dilihat dari efektivitas Aplikasi JAIM.

\section{a. Efek Kognitif}

Dalam kegiatan penggunaan aplikasi JAIM masih sangat mudah dan bermanfaat bagi para Agen sebagai upaya mensosialisasikan program-program serta kemajuan-kemajuan yang telah dicapai oleh aplikasi JAIM jiwasraya di kota Pekanbaru. Upaya-upaya yang dilakukan oleh agen jiwasraya dalam melaksanakan fungsi sebagai media informasi salah satunya dengan bekerjasama dengan media-media massa yang seperti aplikasi JAIM. Hal ini sebagaimana dikemukakan informan 1 bahwa:

“..........Aplikasi JAIM yang digunakan menurut saya masih kurang efektif karena masih banyak agen yang kurang memahami aplikasi JAIM, padahal aplikasi ini sangat membantu agen untuk mendapatkan informasi-informasi data nasabah, baik pemegang polis,dan agen bisa mengisi PKAJ online dan membuat proposal baru. Walaupun kadang sistem aplikasi JAIM perlu di sempurnakan lagi.(Wawancara dengan Senior Agency Manager (SAM) ,02 Mei 2019).

\section{b. Efek Afektif}

Media Informasi aplikasi JAIM yang digunakan oleh agen PT. Asuransi Jiwasraya(persero) memebawa efek perubahan pada agen di era digital ,media online sehinggaagen merasa senang,tapi sebagaian agen masih merasa itu beban dan menyulitkan rose untuk bekerja agen bisa merakap data nasabah dan tidak perlu lagi secara manual/tertulis ,meulis data prospek di buku harian,cukup dengan menggunaan aplikasi JAIM.komunikasi yang disampaiakan pada proses menyampaikaan informasi, ide,atau gagasan kepada semua agen dan sebagai sarana menampaikan ide komunikasi yang efektif tentu sangat dibutuhkan sehingga tujuan aplikasi JAIM ini tercapai. 


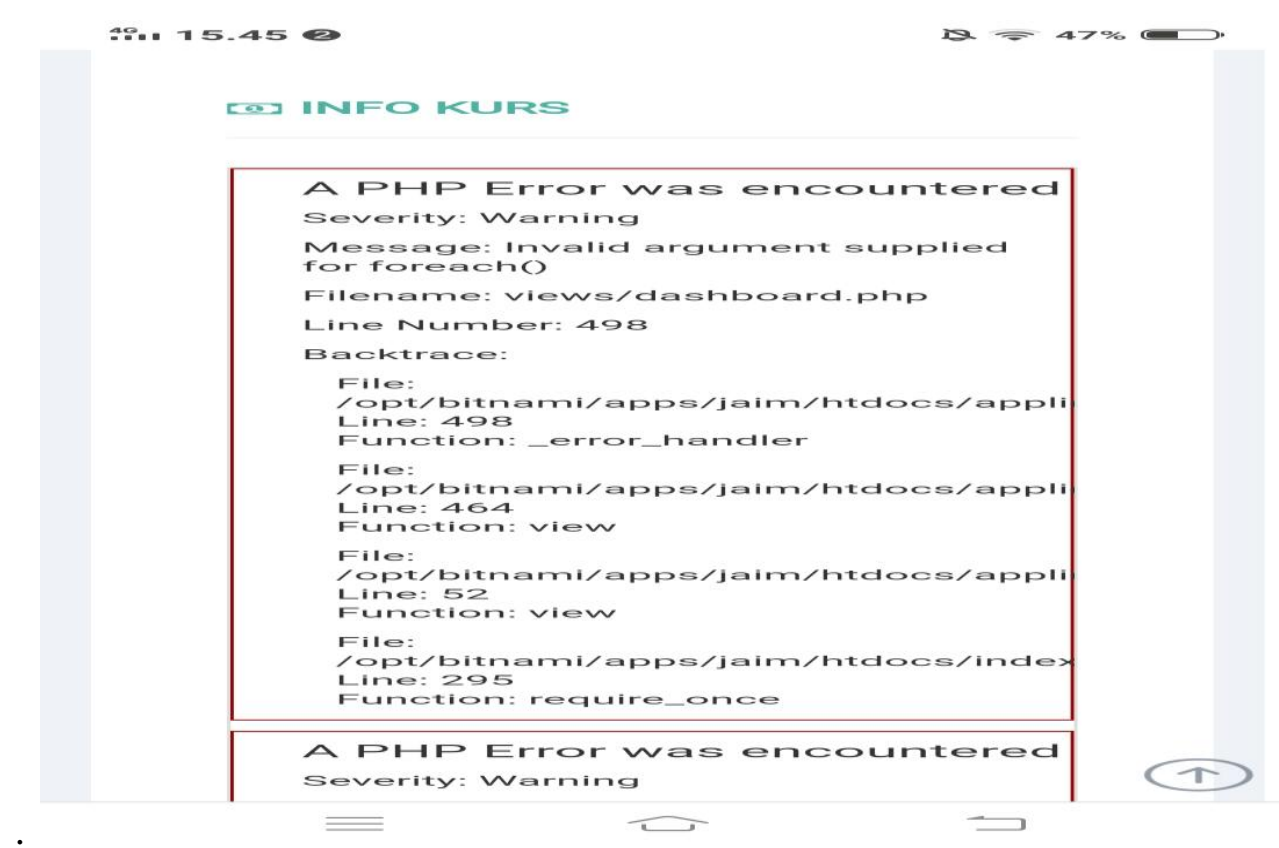

Gambar 1.1: Aplikasi JAIM Error System

\section{Efek Behavioral}

Aplikasi JAIM membaw efek behavioral pada setiap agen yang memiliki keterampilan dan manfaat bagi diri. Keterampilan unuk mau belajar dan menguasai teknologi di era digital semua agen harus bisa karena apa yang diberikan oleh instruktur, senior agency manager dapat mencapai tujaun penggunaan aplikasi JAIM.Pada kenyataannya tidak semua agen mau menggunakan aplikasi JAIM, bahkan sampai saat ini masih ada yang memiliki sifat acuh tak acuh agen. Jika dilihat dari rekapitulasi kinerja agen sangat minim sekali kegiatan atau aktivitas dari penggunaan aplikasi JAIM. Berdasarkan hasil Wawancara yang dilakukan peneliti efek Behavioral aplikasi JAIM dalam kegiatan agen dapat mengevaluasi unit kerja atau unit produksi pendapatan agen setiap bulan.

".........sebagian agen masih ada yang bertanya kepada saya sebagai operasional dikantor, mereka menanyakan laporan unit produksi agen, pendapatan agen/komisi. Padahal itu bisa dilihat diaplikasi JAIM tanpa harus bertanya kebagian opersionalnya (Wawancara, Puji Lestari 02 Mei 2019)

\section{Aplikasi JAIM}

JAIM adalah Aplikasi yang diperuntukkan Mitra Kerja agen Jiwasraya. Aplikasi JAIM ini bisa dibuka menggunakan ID dan Pasword No Lisensi Agen yang aktif. Didalam aplikasi JAIM terdapat beberapa menu antara lain:

1. Beranda; pada aplikasi JAIM tersedia beranda dan profil agen,foto agen,ada tampilan totall polis agen yang aktif dan rata rata komisi perbulan. 


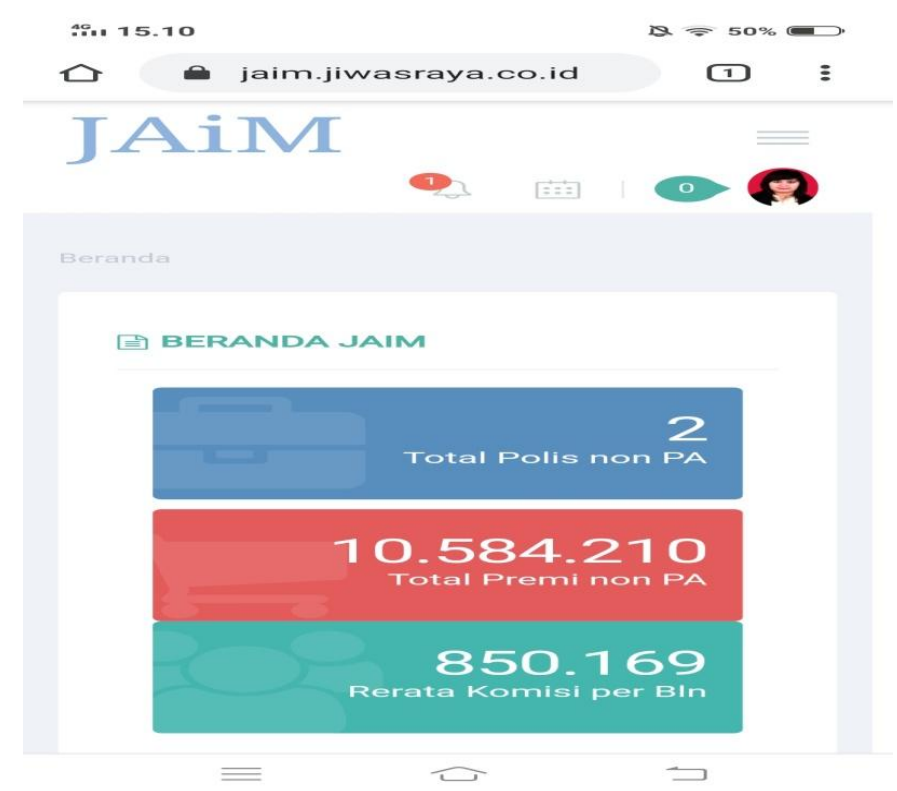

Gambar 1.2:

\section{Beranda Jaim}

2. Pencapaian; produktifnya agen akan dilihat pada pencapaian agen setiap bulannya

3. Prestasi agen; agen yang memenuhi target capaian penjualan polis tertinggi senasional bisa men cek status prestasi agen apakah dapat reward tour setiap tahunnya

4. Kontes; agen bisa melihat reward tahunan ,top polis, jumlah polis jumlah premi,area office dan unit kerja organisasi

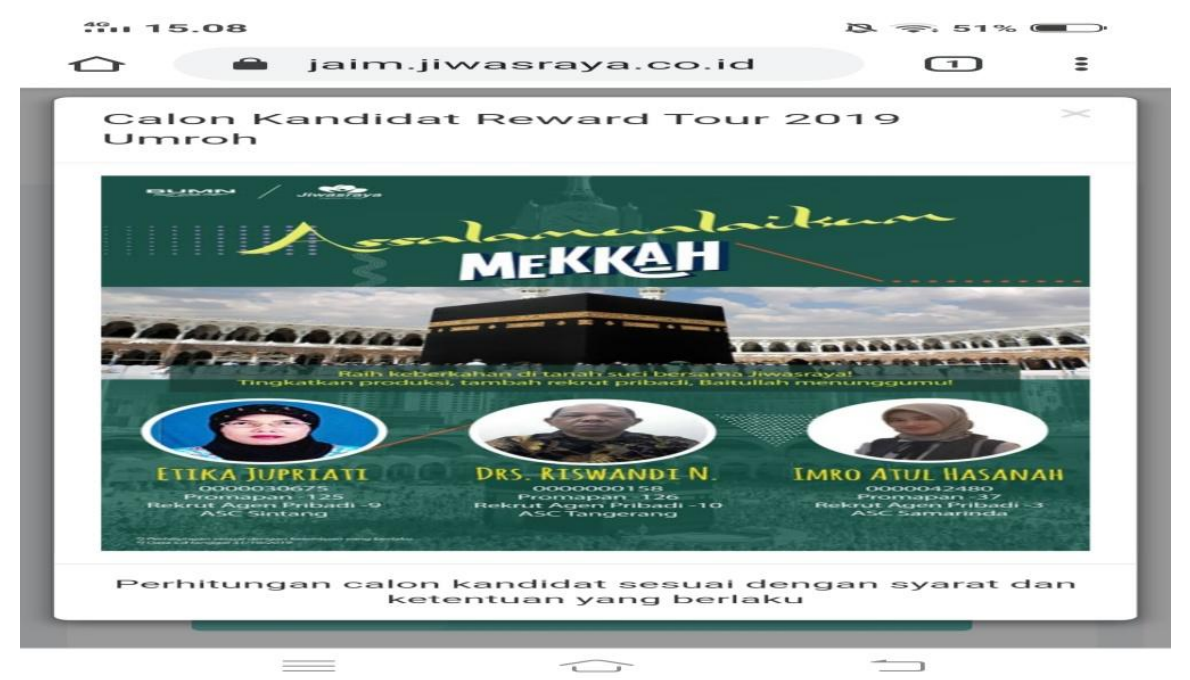

Gambar1.3 : Prestasi Dan Reward Agen

5.Workbook; agen bisa membuat agenda pribadi, agenda binaan, jadwa prospek, data nasanah,ulang tahun nasabah, jatuh tempo benefit dan jatuh tempo premi

6.Buat Proposal Baru; agen bisa membuat proposal

7.Learning; agen bisa mengetahui panduan penggunaan aplikasi jaim,brosur js promapan

Materi bussiness oportunity preentasion,materi entrepreunership dll.

8.Espaj;daftar spaj

9.EKPAJ;perjanjian kerja asuransi jiwasraya

10.My Pro Sales.;manual book 


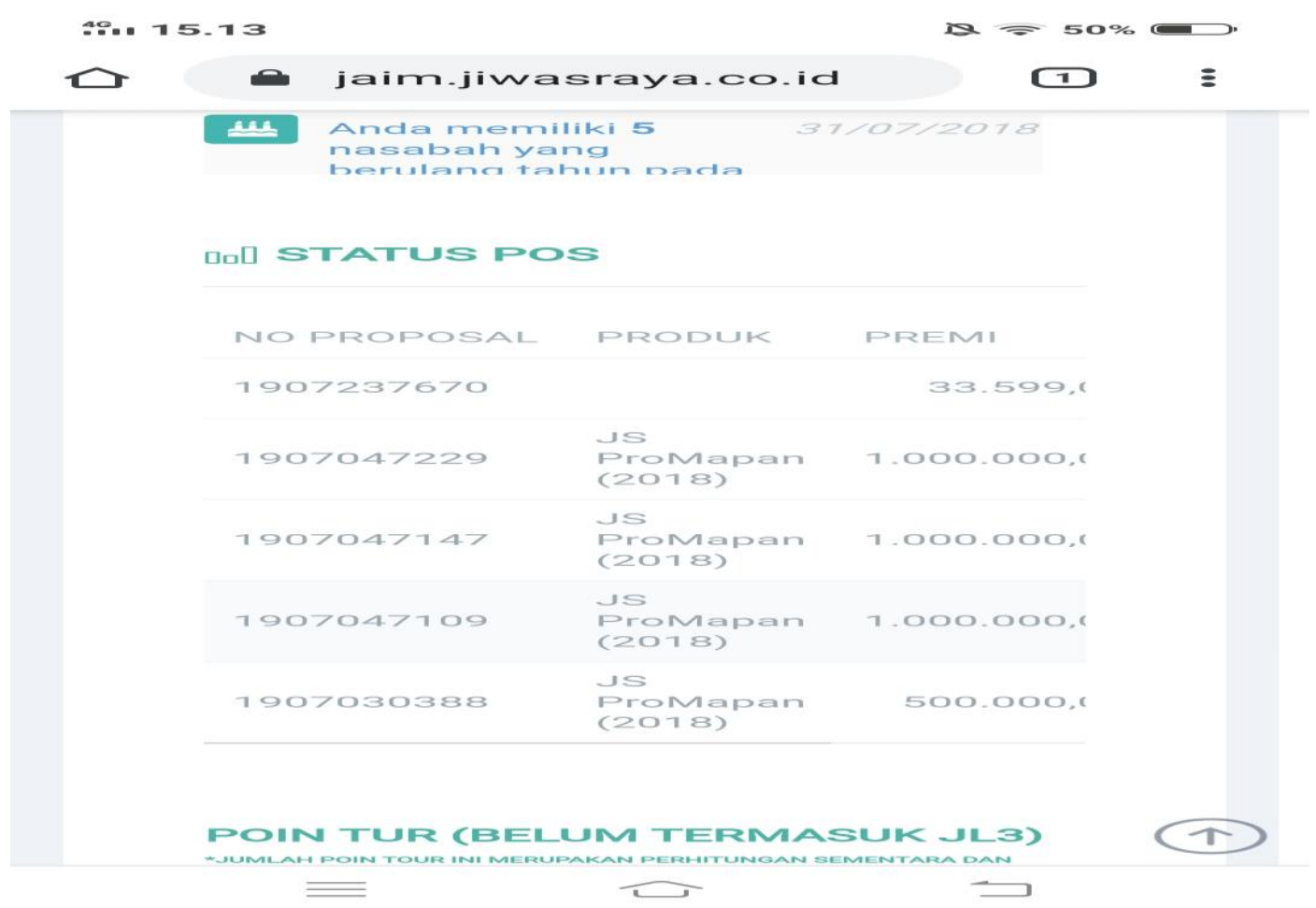

Gambar 1.4: No.proposal, premi dan produk

JAIM sebagai fasilitator media informasi yang sangat bermanfaat sebagai media untuk mengoperasikan pengolahan data atau kegiatan lainnya,seperti: membuat mengolah file atau dokumen. Aplikasi JAIM sebagai media informasi agen yang menjadi perantara dalam kegiatan agen jiwasraya dan nasabah, pengumpulan bahan informasi juga dokumentasi dari efektivitas aplikasi (JAIM) di kota Pekanbaru. Kegiatan tersebut merupakan salah satu kegiatan yang dilakukan oleh bagian IT atau teknisi Jiwasraya.

\section{Kesimpulan}

Berdasarkan hasil penelitian dapat disimpulkan bahwa Efektivitas Komunikasi aplikasi JAIM ( Jiwasraya Agency Information Sistem) Media informasi Agen di PT. Asuransi Jiwasraya (persero) Pekanbaru memaparkan tiga efek dalam aplikasi JAIM : 1). Efek Kognitif; pemahaman agen terhadap aplikai JAIM masih belum maksimal secara keseluruhan, adanya persepsi-persepsi yang berbeda dengan agen yang lainnya atau berbeda pendapat. 2). Efek Afektif;perubahan era digital dan media online yang signifikan memberikan efek kepada Jiwasraya dalam menciptakan aplikasi JAIM yang diperuntukkan kepada agen, agen merasa senang dengan adanya aplikasi JAIM karena memudahkan agen untuk mendapatkan data-data nasabah dan lain-lain, disatu sisi aplikasi JAIM masih sering error sehingga kurang efektif. 3). Efek Behavioral; pada aplikasi JAIM perlu ditambahakan menu aplikasi untuk nasabah sehingga member efek yang lebih baik lagi karena nasabah bisa mengakses kapanpun untuk melihat jatuh tempo premi dan transaksi lainnya

\section{Daftar pustaka}

Andi Prastowo. (2011). Metode Penelitian Kualitatif dalam Perspektif Rancangan

Penelitian. Jogjakarta: Ar-Ruzz Media 
A.W. Widjaja. 2002. Komunikasi dan Hubungan Masyarakat. Jakarta : PT. Bumi Aksara Amelia Anjani, Ike Atikah Ratnamulyani, Ali Alamsyah Kusumadinata jurnal komuniaktio"Penggunaan Media Komunikasi Whatsapp Terhadap Efektivitas Kinerja Karyawan" vil 4.no.1 2018

Demsy Wattimena, Muhammad farid, Jeany Maria Fatima,jurnal kareba: ilmu komunikasi Efektivitas Komunikasi Organisasi Dalam Gaya Kepemimpinan Para Pejabat Eselon Pasca Integrasi Dinas Perhubungan Komunikasi Informatika Di Kabupaten Maluku Tengah vol 2. No.3 juli 2013

Effendi, Muhammad Rizka Maulana. 2014. Modul Ajaran AN.132515 Sistem Informasi Manajemen. Politeknik Negeri Sriwijaya. Palembang

Effendy, Onong Uchjana. (2013). Ilmu Komunikasi Teori dan Praktek.Bandung : PT Rosdakarya

Gitosudarmono, Indriyo. 2000. Manajemen Pemasaran. Edisi II, BPFE, Yogyakarta. Husein, Umar, 2005, Riset pemasaran dan Perilaku Konsumen, Jakarta: PT Gramedia Pustaka Utama

Mukhtar, 2013. Metode Penelitian Deskriptif Kualitatif. Jakarta Selatan: Referensi. Moleong , Lexy J. 2006.Metodologi Penelitian Kualitatif. Bandung: PT. Remaja Rosdakarya. Sutarman. 2009. Pengantar teknologi Informasi. Jakarta : Bumi Aksara.

Rakhmat, Jalaludin. 2013. Psikologi Komunikasi. Bandung: PT. Remaja Rosda Karya

Sari putri novita,Muhanad Firdaus ,jurnal Efektivitas Komunikasi Aplikasi Telegram Sebagai Media Informasi Pegawai Pt.Pos Indonesia (Persero) Kota Pekanbaru: Jom Fisip Vol. 5 No. 1 April 2018 